\title{
ANALISIS KEPUASAN KONSUMEN TERHADAP PRODUK SEMBAKO PADA MINIMARKET JUAN DI KECAMATAN BENAI KABUPATEN KUANTAN SINGINGI
}

\author{
Mulyeni Fitri ${ }^{1}$, Jamalludin ${ }^{2}$, dan Chezy WM Vermila ${ }^{3}$ \\ ${ }^{1,2,3}$ Staf Pengajar Program Studi Agribisnis \\ Chezywmvermila16@gmail.com
}

\begin{abstract}
The purpose of this study was to determine the behavior and consumer satisfaction of consumers of basic food products at the Juan minimarket in Benai District. The method used in this study is the Likert scale and analysis method (IPA) and (CSI) or Consumer Satisfaction Index. The results obtained from consumer behavior towards rice are in the satisfied category, with a total of 16 people from 30 respondents with a percentage of 53.33\%, sugar and cooking oil in the category of Very Satisfied with 23 souls from 30 respondents with a percentage of $76.67 \%$ \%, eggs are in the satisfied category with 25 souls from 30 respondents with a percentage of $83.43 \%$, milk is in the very satisfied category with a total of 17 souls from 30 respondents with a percentage of $56.67 \%$. And the results of the calculation of rice as a whole the value of the index of consumer satisfaction is $69.50 \%$. Where this value is in the consumer satisfaction index range of 50\%-75\%. Sugar consumer satisfaction index value of $59.57 \%$ CSI results are in satisfied criteria, cooking oil consumer satisfaction index value is $72.00 \%$ and CSI results are on very satisfied criteria, egg consumer satisfaction index value is $76.00 \%$ based on CSI results are in the criteria of satisfaction and milk the consumer satisfaction index value is $70.00 \%$.
\end{abstract}

Keywords: Attitudes, Consumer Satisfaction, Basic Needs, Based On The Overall Csi Results, The Criteria Are Satisfied

\begin{abstract}
ABSTRAK
Tujuan penelitian ini adalah untuk mengetahui perilaku konsumen dan kepuasan konsumen terhadap produk sembako pada minimarket Juan di Kecamatan Benai. Metode yang digunakan dalam penelitian ini adalah skala likert dan metode analisis (IPA) dan (CSI) atau Indeks Kepuasan Knsumen. Hasil yang diperoleh prilaku konsumen terhadap beras berada pada kategori puas, dengan jumlah 16 jiwa dari 30 responden dengan 53,33\%, gula dan minyak goreng berada pada kategori Sangat dengan jumlah jiwa 23 jiwa dari 30 responden dengan 76,67\% , telur berada pada kategori puas dengan jumlah jiwa 25 jiwa dari 30 responden dengan $83,43 \%$, susu berada pada kategori sangat Puas dengan jumlah 17 jiwa dari 30 responden dengan 56,67\%. Dan hasil perhitungan secara keseluruhan nilai indeks kepuasan konsumen adalah 69,50\%. Dimana nilai ini berada pada range indeks kepuasan konsumen 50\%-75\%. Berdasarkan hasil CSI secara keseluruhan berada pada kriteria puas, gula nilai indeks kepuasan konsumen sebesar 59,50\% hasil CSI berada pada kriteria puas, minyak goreng nilai indeks kepuasan konsumen adalah 59,50 berdasarkan hasil CSI berada pada kriteria puas, telur nilai indeks kepuasan konsumen adalah $83,02 \%$ berdasarkan hasil CSI berada pada kriteria sangat puas dan susu nilai indeks kepuasan konsumen adalah 68,07\%. Berdasarkan hasil CSI secara keseluruhan berada pada kriteria puas.
\end{abstract}

Kata Kunci : Sikap, Kepuasan Konsumen, Sembako

\section{PENDAHULUAN}

Pertumbuhan penduduk adalah keseimbangan yang dinamis antara kekuatan-kekuatan yang menambah dan kekuatan-kekuatan yang mengurangi jumlah penduduk (Rohani, 2016).
Pertumbuhan penduduk akan menjadi beban pemerintah karena setiap jiwa membutuhkan kebutuhan hidup seperti sandang, pangan, penyediaan sarana dan prasarana sekolah serta lapangan kerja (Nur Rahmi Hamzah, 2017). Menurut Maslow 
(1954), manusia akan senantiasa memenuhi kebutuhan dasarnya secara berjenjeng mulai dari kebutuhan yang bersifat fisiologis, kebutuhan akan rasa aman, kebutuhan akan rasa memiliki-dimiliki dan cinta, kebutuhan akan penghargaan, hingga kebutuhan akan aktualisasi diri.

Bertambahnya jumlah penduduk maka akan secara otomatis akan terjadi peningkatan kebutuhan akan pangan. Kebutuhan pangan merupakan kebutuhan pokok bagi manusia (Heni Susilowati, 2014). Sembako adalah singkatan dari sembilan bahan pokok yang terdiri atas berbagai bahan-bahan makanan dan minuman yang secara umum sangat dibutuhkan masyarakat Indonesia. Tanpa sembako kehidupan rakyat Indonesia bisa terganggu karena sembako merupakan kebutuhan pokok utama sehari-hari yang wajib ada dijual bebas di pasar (Vermila, 2016).

Sesuai dengan keputusan mentri Industri Perdagangan no.115/ MPP/ Kep/ 1998 tanggal 27 Februari 1998, yaitu antara lain : 1) beras dan sagu, 2) jagung, 3) sayursayuran dan buah-buahan, 4) daging baik sapi atau pun ayam, 5) susu, 6) gula pasir, 7) garam yang mengandung yodium, 8) minyak goreng, 9) minyak tanah atau gas elpiji.

Mini Swalayan/Minimarket adalah sarana/tempat usaha untuk melakukan penjualan barang-barang kebutuhan seharihari secara eceran langsung kepada pembeli akhir dengan cara swalayan yang luas lantai usahanya kurang dari $400 \mathrm{~m} 2$. Bisnis retail moderen mulai bangkit pada tahun 1999 setelah hadirnya Hypermarkert, Carrefour dan Continent. (Abdul Kadir Aslam, 2017).

Berbelanja di minimarket semakin digemari seiring perubahan orientasi berbelanja masyarakat perkotaan. Dulu konsumen selalu mencari harga murah, namun dengan kemajuan dan pertumbuhan perekonomian kota, harga murah tidak menjadi pertimbangan utama. Faktor kenyamanan dalam berbelanja menjadi daya tarik tersendiri yang sangat diminati dalam dekade terakhir. Hal ini yang membuat konsumen lebih memilih untuk berbelanja di pasar moderen dari pada ke warung atau ke toko di pasar tradisional (Abdul Kadir Aslam, 2017).

Minimarket Juan adalah salah satu minimarket yang ada di Kecamatan Benai berlokasi di Jalan Imam Munandar 03 Pasar Benai. Minimarket Juan saat ini sudah melakukan usahanya secara sejak tahun 2009 hingga saat ini. Minimarket Juan telah memiliki cabang yang terletak di Jalan Jendral Sudirman Pasar Benai. Minimarket Juan melakukan usaha ekonomi produktif yang berdiri sendiri yang dilakukan oleh perorangan atau jenis Minimarket mandiri. Minimarket mandiri adalah toko yang melakukan kegiatan usaha di bidang Minimarket melalui sistem manajemen dan sistem pendistribusian yang dikelola secara mandiri. Menjual berbagai jenis barang secara eceran, dimana Minimarket ini melakukan kesepakatan kerja antara produsen barang dagangan dengan perusahan distributor dalam pemasaran dan penjualan barang di areanya, pengambilan barang oleh Minimarket kepada produsen akan di bayar setelah dua minggu barang diatar dan setiap satu kali seminggu barang akan di periksa langsung ke toko oleh produsen barang dagangan (keagenan).

Keputusan pembelian adalah tindakan dari konsumen untuk mau membeli atau tidak terhadap produk. Dari berbagai faktor yang mempengaruhi konsumen dalam melakukan pembelian suatu produk atau jasa, biasanya konsumen selalu mempertimbangkan kualitas, harga dan produk yang sudah dikenal oleh masyarakat (Kotler dan Amstrong, 2008).

Kepuasan konsumen merupakan salah satu faktor penting yang harus diperhatikan agar barang dan jasa yang dihasilkan bisa langsung habis terjual, Tolak ukur kepuasan konsumen adalah kesesuian harapan dengan kinerja yang didapatkan. Menurut Kotler (2000), kepuasan konsumen merupakan tingkat perasaan seseorang setelah membandingkan antara kinerja produk yang ia rasakan dengan harapannya. 
Berdasarkan alasan di atas, maka penulis telah melakukan penelitian dengan judul "Analisis Kepuasan Konsumen Terhadap Produk Sembako Pada Minimarket Juan di Kecamatan Benai Kabupaten Kuantan Singingi”.

\section{RUMUSAN MASALAH}

1. Bagaimana prilaku konsumen sembako di Minimarket Juan?

2. Bagaimana tingkat kepuasan konsumen yang berbelanja sembako di Minimarket Juan?

\section{TUJUAN PENELITIAN}

Adapun tujuan yang akan dicapai dalam penelitian ini adalah :

1. Untuk mengetahui perilaku konsumen sembako di Minimarket Juan.

2. Untuk menganalisis tingkat kepuasan konsumen yang berbelanja produk sembako di Minimarket Juan.

\section{RUANG LINGKUP PENELITIAN}

Penelitian ini dilakukan di Minimarket Juan, dan penelitian ini menitikberatkan pendekatan dari sisi konsumen yang berbelanja sembako di Minimarket Juan dan fokus pada kepuasan pelanggan terhadap produk sembako hanya terhadap produk beras, gula, minyak goreng, Telur, dan susu yang ada di Minimarket Juan.

\section{METODE PENELITIAN}

Penelitian ini akan dilakukan di Kecamatan Benai, pada Minimarket Juan yang berlokasi di Jalan Imam Munandar Pasar Benai. Penentuan lokasi ini dilakukan secara sengaja (purposive) dengan mengingat dan menimbang bahwa Minimarket Juan adalah salah satu Minimarket yang cukup banyak dikunjungi oleh konsumen dan penelitian ini dilaksanakan selama 9 bulan yaitu bulan Januari sampai September 2018.

\section{Teknik Pengambilan Sample}

Metode pengambilan sampel yang digunakan dalam penelitian ini adalah metode purposive sampling (teknik pengambilan sampel secara sengaja). Dimana setiap orang yang berbelanja sembako minimal paling sedikit tiga macam barang sembako di Minimarket Juan akan dijadikan sampel.

\section{Jenis dan Sumber Data}

Data yang digunakan dalam penelitian ini berupa data primer dan sekunder, baik yang bersifat kuantitatif maupun kualitatif. Data primer yaitu data yang diperoleh melalui penelitian di lapangan baik melalui wawancara maupun penyebaran kuesioner. Data Primer tersebut terdiri dari :

a. Karakteristik konsumen yaitu umur, pendidikan, pendapatan keluarga, pekerjaan, dan jumlah anggota keluarga.

b. Perilaku konsumen terhadap produk sembako yang ada di Minimarket Juan,

c. Kepuasan Konsumen yang terdiri dari harga, jenis, higienis, aroma dan kemasan.

Data sekunder terdiri dari gambaran umum daerah penelitian, pendidikan penduduk, dan mata pencarian penduduk.

\section{Metode Analisis Data}

Analisis data dilakukan secara kualitatif dan kuantitatif. Data kualitatif di sajikan dalam uraian atau deskriptif, sedangkan data kuantitatif akan disajikan dalam bentuk tabulasi. Perhitungan data dilakukan pada Microsoft Exel. Penelitian ini menggunakan alat analisis berupa Skala Likert, Important dan Performance Analysis, dan Metode Indeks Kepuasan Pelanggan atau Costumer Satisfaction Index(CSI).

\section{Perilaku Konsumen Terhadap Produk Sembako Di Minimarket Juan}

Skala likert menunjukkan tanggapan konsumen terhadap pilihan yang dibuat berjenjang, mulai dari intensitas paling rendah sampai paling tinggi. Dalam penelitian ini digunakan skala likert bertingkat empat, tingkat kepuasan 
konsumen terhadap produk sembako di Minimarket Juan. Pada pokok-pokok skala tersebut memakai kategori jawaban dan pertanyaan pada berikut.

Tabel 1: Skor konsumen di Minimarket Juan Kecamatan Benai

\begin{tabular}{|c|l|c|}
\hline No & \multicolumn{1}{|c|}{ Kategori } & Skor \\
\hline 1 & Sangat Puas & 4 \\
\hline 2 & Puas & 3 \\
\hline 3 & Kurang puas & 2 \\
\hline 4 & Tidak Puas & 1 \\
\hline
\end{tabular}

Analisis sikap untuk masing-masing responden yaitu jumlah pertanyaan 9, skor tertinggi 4 dan skor terendah 1 , maka besar kisaran perhitungan adalah dari total nilai pokok-pokok skala tersebut dikelompokkan menjadi 4 kategori yakni sangat penting, penting, biasa, tidak penting. Untuk mendapatkan 4 kategori tersebut dilakukan dengan menggunakan Rumus :

Skormaksimum-Skorminimum- 0,01

\section{Jumlah Kategori}

Analisis sikap untuk masing-masing responden yaitu jumlah item indikator 9, skor tertinggi 4 dan skor terendah 1, maka besar kisaran perhitungan adalah :

Skor maksimum $\quad: 4 \times 4=16$

Skor minimum $\quad: 4 \times 1=4$

Besar kisarannya adalah :

$$
\frac{16-4}{4}-0,012,99
$$

Berdasarkan kisaran diatas, maka tingkat nilai pada masing-masing responden mengenai kepuasan konsumen terhadap produk sembako di Minimarket Juan Kecamatan Benai di bagi menjadi 4 kategori yaitu :

Tabel 2: Indikator skor penilaian

\begin{tabular}{|c|c|c|c|c|}
\hline \multirow{4}{*}{ Indikator } & \multicolumn{4}{|c|}{ Skor Penilaian } \\
\cline { 2 - 5 } & $\begin{array}{c}\text { Sangat } \\
\text { Puas }\end{array}$ & Puas & $\begin{array}{c}\text { Kurag } \\
\text { Puas }\end{array}$ & $\begin{array}{c}\text { Tidak } \\
\text { Puas }\end{array}$ \\
\cline { 2 - 5 } & $13-$ & $10-$ & $7-$ & $4-$ \\
& 15,99 & 12,99 & 9,99 & 6,99 \\
\hline
\end{tabular}

\section{Kepuasan Konsumen}

Analisis ini digunakan menganalisa identitas umum responden, proses keputusan konsumen pembelian konsumen, dan faktor yang mempengaruhi proses pembelian pada Minimarket Juan menggunakan analisis Important And Performance Analysis dan Costumer Satisfaction Index sebagai berikut :

Nilai Bobot Tingkat Kepentingan (y)

\begin{tabular}{|c|c|}
\hline Tingkat Kinerja $(\mathrm{X})$ & Skor (bobot) \\
\hline Tidak Puas & 1 \\
\hline Kurang Puas & 2 \\
\hline Puas & 3 \\
\hline Sangat Puas & 4 \\
\hline
\end{tabular}

Nilai Bobot Tingkat Kinerja (x)

Dalam analisis data ini terdapat dua buah variabel yang diwakili oleh huruf $X$ dan $\mathrm{Y}$, dimana $\mathrm{X}$ menunjuk ranting kinerja suatu produk, sementara Y menunjukkan tingkat kepentingan konsumen. Bobot penilaian atribut produk setiap responden (Xi) dan bobot penilaian kepentingan setiap responden (Yi) di rata-rata dan di formulasikan ke dalam diagram kartesius. Masing-masing atribut diposisikan dalam sebuah diagram, dimana skor rata-rata penilaian terhadap kinerja $(\bar{X})$ menunjukkan posisi suatu atribut pada sumbu $X$, sementara posisi atribut pada sumbu $\mathrm{Y}$ di tunjukkan oleh skor rata-rata tingkat kepentingan atribut $(\bar{Y})$.

Dengan rumus:

$$
\begin{aligned}
\bar{X} & =\underline{\underline{\Sigma \mathrm{Xi}}} \text { dan } \\
\bar{Y} & =\underline{\mathrm{n}}
\end{aligned}
$$

n

Dimana :

$\bar{X}=$ bobot rata-rata tingkat penilaian kinerja atribut produk

$\bar{Y}=$ bobot rata-rata penilaian kepentingan pelanggan

$\mathrm{n}=$ jumlah responden

Diagram kartesius yang dimaksud disini adalah suatu bangun yang dibagi menjadi empat bagian yang dibatasi oleh dua buah garis yang berpotongan tegak lurus pada suatu titik $(\overline{\bar{X}}, \overline{\bar{Y}})$. Nilai $\overline{\bar{X}}$ dan $\overline{\bar{Y}}$ 
digunakan sebagai pasangan koordinat titiktitik atribut yang memposisikan suatu atribut terletak dimana pada diagram kartesius. Dengan rumus :

$$
\begin{aligned}
& \overline{\bar{X}}=\frac{\sum_{i=1}^{n} X i}{\mathrm{n}} \text { dan } \\
& \overline{\bar{Y}}=\frac{\sum_{\mathrm{n}}^{n} Y i}{\mathrm{n}}
\end{aligned}
$$

Dimana :

$\overline{\bar{X}}=$ rata-rata dari rata-rata bobot tingkat kinerja responden atribut produk.

$\overline{\bar{Y}}=$ rata-rata dari rata-rata tingkat kepentingan responden atribut produk

$\mathrm{K}=$ banyaknya atribut yang mempengaruhi kepuasan pelanggan

Penjabaran diagram Kartesius ditunjukkan pada gambar 2 berikut (Supranto, 2001).

Rentan skala yang akan digunakan disesuaikan dengan rumus sebagai berikut :

Rs $\quad=\frac{(m-n)}{b}$

Dimana :

Rs $=$ Rentang Skala

$\mathrm{m}=$ skor tertinggi

$\mathrm{n}=$ skor terendah

\begin{tabular}{|c|c|c|}
\hline \multicolumn{2}{|l|}{ Indikator } & Skor Penilaian \\
\hline \multicolumn{2}{|l|}{ Sangat Penting } & $106-91$ \\
\hline \multicolumn{2}{|l|}{ Penting } & $90-73$ \\
\hline \multicolumn{2}{|l|}{ Kurang Penting } & $72-55$ \\
\hline \multicolumn{2}{|l|}{ Tidak Penting } & $54-38$ \\
\hline \multicolumn{3}{|c|}{ Tabel 2. Skor Penilaian Tingkat Kinerja Atribut } \\
\hline \multicolumn{3}{|c|}{ Indikator $\quad$ Skor Penilaian } \\
\hline Sangat Puas & 113 & $-95,25$ \\
\hline Puas & 94,25 & 77,5 \\
\hline Kurang Puas & 76,5 & 59,75 \\
\hline
\end{tabular}

$\mathrm{b}=$ jumlah kelas

Rentang skala pada tingkat kepentingan adalah :

Skor Penilaian Tingkat Kepentingan Atribut

\begin{tabular}{llll}
\hline Tidak Puas & $42 \quad-58,75$
\end{tabular}

Tingkat kepuasan responden secara menyeluruh dapat dilihat dari kriteria tingkat kepuasan. Kepuasan tertinggi dicapai bila CSI menunjukkan $100 \%$. Rentang kepuasan berkisar dari 0-100 \%. Berdasarkan Simamora (2005), untuk membuat skala linier numerik, pertamatama kita cari rentang skala:

(RS) dengan rumus :

$$
\mathrm{RS}=\frac{m-n}{b}
$$

Dimana :

$\mathrm{m}=$ skor tertinggi 4

$\mathrm{n}=$ skor terendah 1

$\mathrm{b}=$ jumlah kelas atau kategori yang akan dibuat

Untuk penelitian ini, rentang skalanya adalah :

RS $=\frac{100 \%-0 \%}{4}=20 \%$

Berdasarkan rentang skala di atas, maka kriteria kepuasannya adalah sebagaiberikut :

$0 \%<\mathrm{CSI} \leq 25 \% \quad=$ Tidak puas

$25 \%<\mathrm{CSI} \leq 50 \% \quad=$ Kurang puas

$50 \%<\mathrm{CSI} \leq 75 \% \quad=$ Puas

$75 \%<\mathrm{CSI} \leq 100 \% \quad=$ Sangat puas

\section{HASIL DAN PEMBAHASAN}

\section{Perilaku Konsumen Terhadap} produk sembako

\section{a) Perilaku konsumen beras}

Berada pada kategori puas terhadap beras yang terdapat pada Minimarket Juan di kecamatan benai dengan jumlah 16 jiwa dari 30 responden dengan 53,33\%, yang berada pada kriteria skor 10 12,99\%.

\section{b) Prilaku konsumen telur}

Berada pada kategori puas terhadap telur yang dijual minimarket Juan dengan jumlah jiwa 25 jiwa dari 30 responden dengan $83,43 \%$, yang berada pada kriteria skor $10-12,99$.

\section{c) Perilaku konsumen Susu}

Berada pada kategori sangat Puas terhadap susu yang terdapat di Minimarket 
Juan dengan jumlah 17 jiwa dari 30 responden dengan $56,67 \%$, yang berada pada kriteria skor 13-15,99.

\section{Indeks Kepuasan Konsumen atau CSI Beras}

Indeks kepuasan konsumen atau Cutomer Satisfaction Index beras.

\begin{tabular}{lcccc}
\hline Atribut & (MIS) & (MSS) & (WF) & (WS) \\
\hline Harga & 3,53 & 3,20 & 0.27 & 0,86 \\
Jenis & 3,46 & 2,93 & 0,26 & 0,76 \\
Higenis & 3,16 & 2,36 & 0,24 & 0,56 \\
Aroma & 2,83 & 2,93 & 0,21 & 0,61 \\
\hline TOTAL & $\mathbf{1 2 , 9 8}$ \\
\hline Weight Average Total (WAT) & $\mathbf{2 , 7 9}$ \\
\hline CSI \\
\hline \multicolumn{5}{c}{$\mathbf{0 , 6 9 5}=\mathbf{6 9 . 5 0 \%}$} \\
Berdasarkan hasil perhitungan secara \\
keseluruhan nilai indeks kepuasan \\
konsumen adalah 69,50\%. Dimana nilai ini \\
berada pada range indeks kepuasan \\
konsumen 50\%-75\%. Berdasarkan hasil \\
CSI secara keseluruhan berada pada \\
kriteria puas. Hal ini membuktikan bahwa \\
konsumen beras merasa tingkat \\
kepentingan dan kinerja beras sudah \\
memenuhi kategori konsumen dengan nilai \\
kategori puas. Yang mana kategori puas \\
terdapat pada jenis beras pandan wangi \\
dan pandan wangi ini memiliki aroma \\
yang harum yang membuat konsumen \\
merasa puas atas atribut beras ini.
\end{tabular}

2. Indeks kepuasan konsumen atau Cutomer Satisfaction Index atribut gula.

\begin{tabular}{lcccc}
\hline Atribut & MIS & MSS & (WF) & (WS) \\
\hline Harga & 3,20 & 3,26 & 0,34 & 1,10 \\
Merek & 2,53 & 2,16 & 0,27 & 0,58 \\
Ukuran & 2,30 & 2,23 & & \\
Kristal & & & 0,24 & 0,53 \\
Kemasan & 1,30 & 1,40 & 0,13 & 0,18 \\
\hline TOTAL & $\mathbf{9 , 3 3}$ & & \\
\hline Weight Average Total (WAT) & $\mathbf{2 , 3 9}$ \\
\hline CSI & $\mathbf{0 , 5 9 5 7}=\mathbf{5 9 . 5 7 \%}$ \\
\hline
\end{tabular}

Berdasarkan hasil perhitungan secara keseluruhan nilai indeks kepuasan konsumen adalah 59,50\%. Dimana nilai ini berada pada range indeks kepuasan konsumen 50\%-75\%. Berdasarkan hasil CSI secara keseluruhan berada pada kriteria puas. Hal ini membuktikan bahwa konsumen menyukai gula curah kekuningkuningan tidak mementingkan merek, kemasannya setra ukuran kristalnya. Harga gula curah kekuning-kuningan ini tidak terlalu mahal dan tidak terlalu murah sehingga konsumen lebih menyukai gula ini.

3. Indeks kepuasan konsumen atau Cutomer Satisfaction Index atribut minyak goreng.

\begin{tabular}{lclll}
\hline \multicolumn{1}{c}{ Atribut } & (MIS) & (MSS) & (WF) & (WS) \\
\hline Harga & 3,10 & 2,06 & 0,32 & 0,65 \\
Merek & 2,80 & 3,50 & 0,29 & 1,01 \\
Kandungan & 2,70 & 3,06 & & \\
komposisi & & & 0,28 & 0,85 \\
Kemasan & 1,26 & 2,86 & 0,13 & 0,37 \\
\hline TOTAL & $\mathbf{9 , 4 5}$ \\
\hline Weight Average Total (WAT) \\
CSI & $\mathbf{0 , 7 2 2}=\mathbf{7 2 , 0 0 \%}$ \\
\hline
\end{tabular}

Berdasarkan hasil perhitungan secara keseluruhan nilai indeks kepuasan konsumen adalah $83,02 \%$. Dimana nilai ini berada pada range indeks kepuasan konsumen 75\%-100\%. Berdasarkan hasil CSI secara keseluruhan berada pada kriteria sangat puas. Hal ini membuktikan bahwa konsumen sudah merasa puas atas atributatribut minyak goreng yang terdapat di Minimarket Juan. Dimana terdapat banyak merek minyak goreng dan berbagai bentuk kemasan yang memudahkan konsumen memilih sesuai selera dan kemampuannya.

4. Indeks kepuasan konsumen atau Cutomer Satisfaction Index atribut telur.

\begin{tabular}{lcccc}
\hline Atribut & (MIS) & (MSS) & (WF) & (WS) \\
\hline Harga & 3,00 & 2,36 & 0,30 & 0,70 \\
Higenis & 1,53 & 2,76 & 0,15 & 0,41 \\
Aroma & 2,36 & 2,90 & 0,24 & 0,69 \\
Kemasan & 2,80 & 2,93 & 0,28 & 0,82 \\
\hline TOTAL & 9,69 \\
\hline Weight Average Total (WAT) & $\mathbf{2 , 6 2}$ \\
\hline CSI & $\mathbf{0 , 6 5 5}=\mathbf{6 5 . 5 0 \%}$ \\
\hline
\end{tabular}

Berdasarkan hasil perhitungan secara keseluruhan nilai indeks kepuasan konsumen adalah 68,07\%. Dimana nilai ini berada pada range indeks kepuasan konsumen 50\%-75\%. Berdasarkan hasil 
CSI secara keseluruhan berada pada kriteria puas. Hal ini membuktikan bahwa konsumen susu merasa tingkat kepentingan dan kinerja telur sudah memenuhi kategori konsumen dengan nilai kategori puas.

5. Indeks kepuasan konsumen atau Cutomer Satisfaction Index atribut susu.

\begin{tabular}{lcccc}
\hline Atribut & (MIS) & (MSS) & (WF) & (WS) \\
\hline Harga & 3,10 & 3,20 & 0,27 & 0,86 \\
Higenis & 3,13 & 3,76 & 0,26 & 0,97 \\
Aroma & 2,50 & 2,90 & 0,21 & 0,60 \\
Kemasan & 2,90 & 2,56 & 0,24 & 0,61
\end{tabular}

\begin{tabular}{|c|c|}
\hline TOTAL & 11,63 \\
\hline (WAT) & 3,04 \\
\hline CSI & $0,76=76,00 \%$ \\
\hline
\end{tabular}

secara keseluruhan nilai indeks kepuasan konsumen adalah $76,00 \%$. Dimana nilai ini berada pada range indeks kepuasan konsumen 50\%-75\%. Berdasarkan hasil CSI secara keseluruhan berada pada kriteria puas. Hal ini membuktikan bahwa konsumen susu merasa tingkat kepentingan dan kinerja beras sudah memenuhi kategori konsumen dengan nilai kategori puas. Karena konsumen merasa puas karena terdapat berbagai jenis susu, berbagai bentuk kemasan yang memudahkan konsumen memilih susu sesuai kebutuhan dan kemampuannya.

\section{KESIMPULAN}

Berdasarkan hasil pembahasan diatas didapatkan beberapa kesimpulan bahwa konsumen sudah merasa puas akan sembako yang terdapat di Minimarket Juan. Dimana sembako tersebut adalah beras, gula minyak, telur dan susu.

\section{DAFTAR PUSTAKA}

Asiam, Abdul Kodir . 2017. Pengaruh Pertumbuhan Minimarket Terhadap Minat Dan Kebiasaan Belanja Masyarakat Di Kelurahan Tamamaung Kota Makassar. Makassar: Universitas Islam Negeri Alauddin.
Ardiansyah. 2008. "Hubungan Minat Membaca Komik Dengan Penyesuaian Diri Pada Siswa SMA" (Skripsi). Surakarta: Fakultas Psikologi UMS.

Blackwell, Engel J. F., R.D dan P.W. Miniard. 1995. Perilaku Konsumen. Jakarta: Binarupa Aksara.

Chezy, Vermila WM. 2017. "Analisis Kepuasan Konsumen yang Berbelanja Sembilan Kebutuhan Bahan Pokok (Sembako) Pada Pasar Tradisional Dan Pasar Moderen Di Kota Pekanbaru" Jurnal Agribisnis Vol 17 No 1. Pekan Baru: Universitas Negeri Riau.

Dewi dan Keni. 2013. "Pengaruh Umur Perusahaan, Profitabilitas, Ukuran Perusahaan dan Leverage Terhadap Pengungkapan Tanggung Jawab Sosial Perusahaan" Jurnal Bisnis dan Akuntansi, 2013.

Harnanda. 2006. Analisis Tingkat Kepuasa Konsumen pada Supermarket Pasar Buah Pekanbaru dan Implikasinya dalam Strategi Pemasaran. Pekanbaru: Universitas Islam Riau.

Heni, Susilowati. 2014. Faktor-Faktor Yang Mempengaruhi Ketahanan Pangan Rumah Tangga Miskin Di Kecamatan Srandakan Bantul. Yogyakarta: Universitas Negeri Yogyakarta.

Kotler, Philip dan Armstrong Gary. 1996. Marketing Management-An Asian Perspective. Singapore: Prentice Hall.

Kotler, Philip. 1991. Manajemen Pemasaran, Analisis, Perencanaan, Implementasi dan Pengendalian. Jakarta: Erlangga.

LS, Camelia. 2002. "Konsumsi Ikan dan Faktor yang Mempengaruhinya Pada Remaja di SMUN 9 Bandung" (Skripsi). Bogor: Fakultas Pertanian, Institut Pertanian.

Nazir, Moh. 1999. Metode Penelitian. Jakarta: Ghalia Indonesia. 
Mowen. 1995. Perilaku Konsumen. Jakarta: Pustaka Ilmu.

P, Kotler. 2002. Manajemen Pemasaran. Jakarta: Prenhallindo.

Riyanto, Bambang. 2001. Dasar-dasar Pembelanjaan Perusahaan. Yogyakarta: BPFE. 